\title{
Early bacterial identification and carbapenemase detection from positive blood culture by mass spectrometry and Blue-Carba test
}

\author{
María Eugenia Cattani $\odot$, Sandra Cogut $\odot$, Sara C. Kaufman $\odot$
}

Sección Microbiología Clínica, División Laboratorio, Hospital Juan A.Fernández, Ciudad Autónoma de Buenos Aires, Argentina

\begin{abstract}
Objectives: In this study, we evaluated a rapid and simple protocol for direct identification of microorganisms with Matrix-Assisted Laser Desorption/Ionization Time of Flight, Mass Spectrometry (MALDI-TOF MS) after a short incubation in solid medium (3 to $5 \mathrm{~h}$ ).

Methods: We have examined a total of 1101 positive blood culture bottles from 782 patients.

Results: We obtained a correct identification in 1037 (94.18\%); 190 (98.44\%) were Staphylococcus aureus, and $386(98.44 \%)$ Enterobacteriaceae. Both are the most frequent etiological agents of sepsis. A total of 1004 bottles were monomicrobial $(96.81 \%)$ and $33(3.18 \%)$, polimicrobial. In the latter we identified at least one species. Two hundred eighty $(27.00 \%)$ organism isolated were considered skin contaminant. Carbapenemase tests were performed with Blue-Carba test in 140 patinas from Gram negative bacilli, we have detected earlier 27 of 29 positive $(93.10 \%)$.

Conclusions: Mass spectrometry by MALDI-TOF MS is very useful to quickly identify the microbial agent and Blue-Carba contribute to adapt the antibiotic therapy to obtain a correct clinical management of the patient with bacteremia.
\end{abstract}

Keywords: MALDI-TOF MS, rapid identification, blood culture, carbapenemase, short incubation

epsis is associated with high mortality rate in adults and children worldwide. Blood cultures continue to be the gold standard for the etiological diagnostic. Considering the emerging resistance mechanisms and the diverse spectrum of organisms, the rapid microbiological identification and the fast resistance mechanisms detection are crucial for optimal management of these infections [1]. Also, it is important to know the local resistance patterns to optimize the empirical treatment. We carry out this work for giving a quick response that allows adequate management of the bacteremic patient, and a decrease in mor- bidity and mortality associated with these serious infections. Techniques to decrease turnaround time to identify the causative agents are imperative for the reduction of mortality due to sepsis. A standard protocol for microbial identification is based on phenotypic aspect and bioochemical patterns. Complete identification is routinely achieved within 18 to $48 \mathrm{~h}$, but may require more time for fastidious or atypical organisms. Introduction of Matrix-Assisted Laser Desorption/Ionization Time of Flight, Mass Spectrometry (MALDITOF MS) changed the general workflow in the clinical microbiology laboratories, had increased speed and

Received: October 11, 2018; Accepted: November 26, 2019; Published Online: January 15, 2020

How to cite this article: . Cattani ME, Cogut S, Kaufman SC. Early bacterial identification and carbapenemase detection from positive blood culture by mass spectrometry and Blue-Carba test. Eur Res J 2020;6(2):154-162. DOI: 10.18621/eurj.469655

Address for correspondence: Sara C. Kaufman, MD., Hospital Juan A.Fernández, Sección Microbiología Clínica, División Laboratorio, Ciudad Autónoma de Buenos Aires, Argentina,E-mail: sarackaufman@gmail.com 
accuracy of microbiological results. In a few minutes, MALDI-TOF MS can allows the analysis of proteins, mainly ribosomal type, for the exact identification of bacteria, mycobacteria and yeasts through the creation of a mass spectrum specific for each microorganism. The mass spectra of test isolates are sequentially compared with those in a reference, database for identification. Depending on the MALDI-TOF MS score, the genus and species identification for an organism may be accurate. Individual mass peaks are used for microorganism identification and provide valuable information for the fingerprinting of bacteria. This technology generates fast and reliable identifications, and has the ability to analyze a large number of isolates simultaneously [2-4].

MALDI-TOF MS could be applied directly to blood cultures. In prospective studies, using different protocols such as Sepsityper (Bruker, Germany) or inhouse procedures for bacterial extraction followed by lysis centrifugation and washing, it is possible to identify almost 72 to $80 \%$ of the microorganisms of positive blood cultures $[2,5,6]$.

The marked increase in the incidence of infections due to antibiotic-resistant Gram-negative bacilli in recent years is of great concern, as patients infected by those isolates might initially receive antibiotics that are inactive against the pathogens $[1,7]$.

The objective of this study is to validate the bacterial identification from patinas obtained from short solid incubation of positive blood cultures, compared to overnight incubation and the rapid carbapenemase detection in Gram-negative bacilli that has clinical and epidemiological implications.

\section{METHODS}

Between 6/1/2014 and 12/31/2016 from 7 am to 2 pm, except weekends, a total of 1101 positive blood culture bottles, aerobic plus/F, anaerobic plus/F and pediatric plus/F, from BACTEC FX (Becton Dickinson, USA) were included. A total of $50 \mu \mathrm{l}$ of broth was taken from the positive bottles and inoculated onto Columbia sheep blood agar plate (bioMerieux, Marcy-1'Ettoile, France) and incubated in a $5 \% \mathrm{CO} 2$ environment at $35^{\circ} \mathrm{C}$. Simultaneously, the Gram stain was done and if structures compatible with anaerobic bacteria were seen, we added other plate in anaerobic condition of incubation. Three hours later, the presence of bacterial growth as patina was controlled and, if it was positive, the MALDI-TOF MS (Bruker Daltonic, Germany) typing was performed; otherwise, the plaque was reincubated and it was observed after $2 \mathrm{~h}$. If the grow was visible, it was proceeded to study. The processing of the patina consisted in transferring an amount of the bacterial patina to a spot of the reusable plate with a wooden stick. One $\mu 1$ of $100 \%$ formic acid (Fluka, Germany), and then $1 \mu \mathrm{l}$ of alpha-cyano-4-hydroxycinnamic acid matrix solution (HCCA, Bruker Daltonik, Bremen, Germany) was added. Calibration was performed using a BTS calibrator following the instructions given in the procedure manual; data was entered according to the software.

Criteria for successful identification were achieved according to manufacturer and international literature [8-10]. The Maldi Biotyper Software version 3.1 (Bruker Daltonik) was used to process the data. The results were compared with the routine identification procedures, including MALDI-TOF MS from overnight incubation in all cases of preliminary acceptable identification.

To classify in true bacteriemia or contamination we rely on medical records according to the criteria of the CDC/NHSN [11].

One hundred and forty gram negative bacilli patinas of hospitalized patients were tested against the Blue-Carba Test (BCT) [7, 12]. This method is based on the hydrolysis of imipenem in a bromothymol blue solution, in order to detect the presence of bacteria producing carbapenemases. The phenotypic confirmation of the presence of carbapenemases was made through the sensitivity profile and the use of different inhibitors (APB, EDTA, DCM-Brit) [13-15]. The carbapenemases isolates, other than Klebsiella pneumoniae carrying KPC, were confirmed molecularly by PCR / DNA sequencing.

\section{RESULTS}

The results are summarized in Table 1. From 1101 positive blood cultures bottles; a valid identification was obtained in 1037 (94.18\%). Two hundred and eighty patinas $(27 \%)$ were considered skin contaminants. A total of 1004 bottles were 
Table 1. Results of the bottles studied

\begin{tabular}{lcc}
\hline Bottles studied & $\mathbf{1 1 0 1}$ & $\mathbf{1 0 0 , 0 0 \%}$ \\
\hline Positive Identification & 1037 & $94.18 \%$ \\
No Score & 64 & $5.82 \%$ \\
Polymicrobials & 33 & $3.18 \%$ \\
Monomicrobials & 1004 & $96.81 \%$ \\
Contaminated & 280 & $27.00 \%$ \\
\hline
\end{tabular}

monomicrobial (96.81\%) and 33 (3.18\%), polimicrobial. In the latter we identified at least one species.

Table 2, shows the groups of microorganisms by gender and species, followed by the total number of these and their percentage of positivity identification, and also the average score of each goup of them.

From 1037 blood cultures bottles, were identified
563 Gram-positive cocci, 453 Gram-negative bacilli, and 21 Gram-positive bacilli. Within this last category, 11 were anaerobes; 7, belonged to the genus Corynebacterium; 3 were included in the other categories (Bacillus cereus and Lactococcus lactis). The remaining $64(5.81 \%)$ patinas showed no results. No yeasts results were obtained between 3 and 5 hours of incubation of the solid media. Whichever the reason was, we did not achieve reliable results or visible patinas.

Of all the patinas studied, more reliable scores were observed in the Gram-negative bacilli, and Staphylococcus aureus since these showed an average score of 2.00. On the other hand, Gram-positive cocci showed an average score of 1.80 (between coagulase negative staphylococci and streptococci).

Table 3 shows the bottles in which microorganisms were considered contaminant. Out of the 140 patinas tested by BCT, 29 were positive, and no false positive ones were obtained. There were two

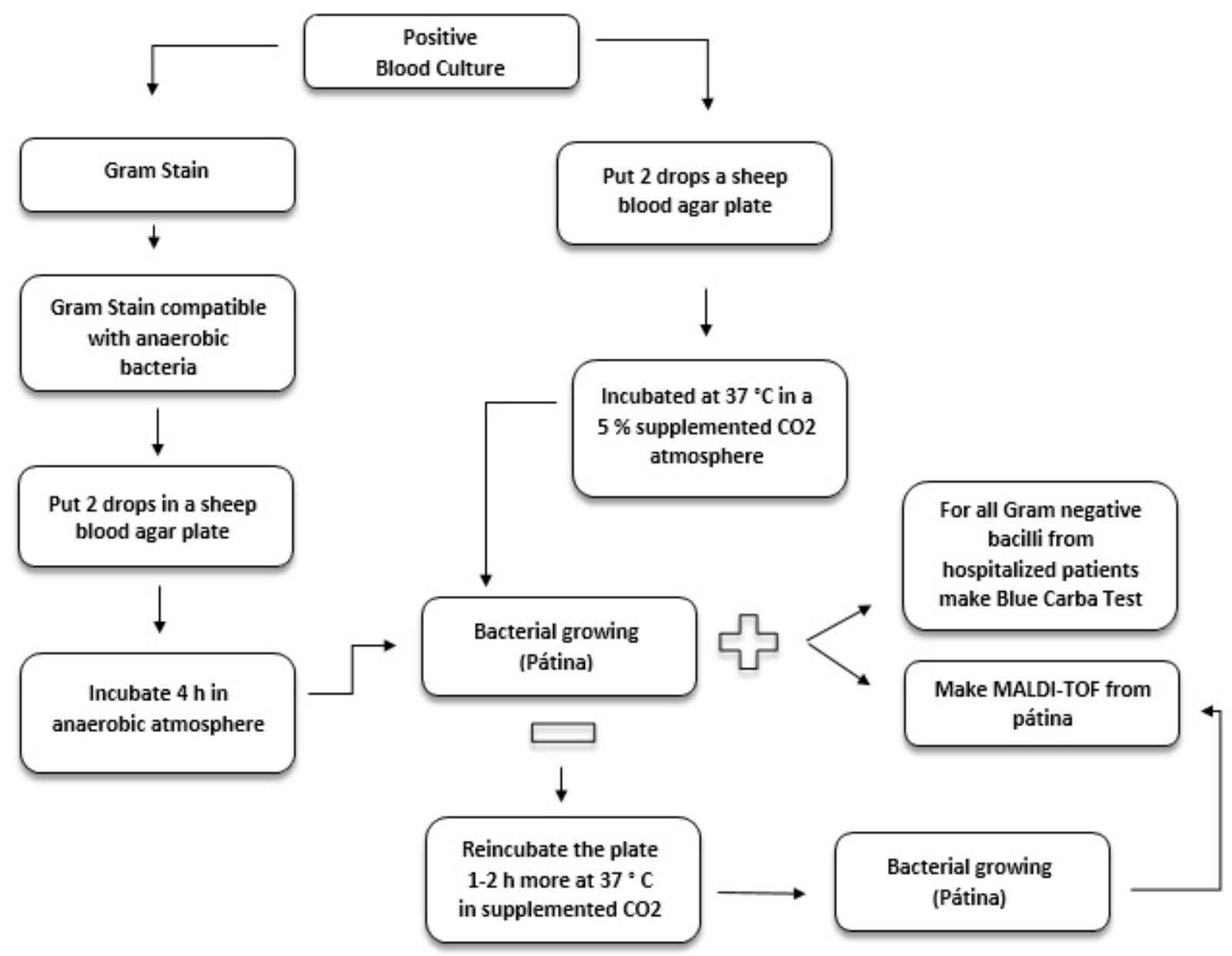

Fig. 1. Workflow diagram. 
Table 2. MALDI-TOF MS identification results at 3 and $5 \mathrm{~h}$-incubation time on solid medium at genus and species levels with average score and \% of identification

\begin{tabular}{|c|c|c|c|c|c|c|}
\hline Microorganisms & Number & $\begin{array}{l}\text { \% of } \\
\text { isolates }\end{array}$ & Id. & No Id. & $\begin{array}{l}\text { Average } \\
\text { score }\end{array}$ & $\%$ of Id. \\
\hline Gram-positive cocci & 610 & & 563 & 47 & & 92.29 \\
\hline Staphylococcus aureus & 193 & & 190 & 3 & 2.01 & 98.44 \\
\hline $\begin{array}{l}\text { Coagulase Negative } \\
\text { Staphylococcus (CNS) }\end{array}$ & 302 & & 262 & 40 & & 86.75 \\
\hline Staphylococcus capitis & 10 & & 8 & 2 & 1.86 & \\
\hline Staphylococcus caprae & 1 & & 1 & & & \\
\hline Staphylococcus cohnii & 2 & & 2 & & 1.7 & \\
\hline Staphylococcus epidermidis & 188 & & 162 & 26 & 1.83 & 86.17 \\
\hline Staphylococcus haemolyticus & 38 & & 35 & 3 & 1.79 & \\
\hline Staphylococcus hominis & 48 & & 36 & 12 & 1.92 & \\
\hline Staphylococcus saprophyticus & 1 & & 1 & & 1.82 & \\
\hline Staphylococcus lugdunensis & 4 & & 4 & & 2.33 & \\
\hline Staphylococcus simulans & 3 & & 3 & & 1.99 & \\
\hline Staphylococcus schleiferi & 1 & & 1 & & 1.68 & \\
\hline Staphylococcus xylosus & 3 & & 3 & & 1.98 & \\
\hline $\begin{array}{l}\text { Staphylococcus } \\
\text { pseudintermedius }\end{array}$ & 2 & & 2 & & 1.98 & \\
\hline Staphylococcus pettenkoferi & 1 & & 1 & & 1.75 & \\
\hline Enterococcus spp. & 49 & & 48 & 1 & & 97.96 \\
\hline Enterococcus faecalis & 35 & & 34 & 1 & 2.05 & 97.14 \\
\hline Enterococcus faecium & 13 & & 13 & & 1.9 & \\
\hline Enterococcus casseliflavus & 1 & & 1 & & 2.24 & \\
\hline Streptococcus spp. & 52 & & 51 & 1 & & 98.07 \\
\hline Streptococcus pneumoniae & 20 & & 19 & 1 & 2.17 & \\
\hline Streptococcus anginosus & 4 & & 4 & & 1.92 & \\
\hline Streptococcus oralis & 6 & & 6 & & 1.92 & \\
\hline Streptococcus constellatus & 1 & & 1 & & 2.14 & \\
\hline Streptococcus gallolyticus & 2 & & 2 & & 1.91 & \\
\hline Streptococcus gordonii & 1 & & 1 & & 2.04 & \\
\hline Streptococcus lutetiensis & 1 & & 1 & & 2.18 & \\
\hline Streptococcus parasanguinis & 3 & & 3 & & 1.95 & \\
\hline Streptococcus salivarius & 7 & & 7 & & 1.99 & \\
\hline Streptococcus agalactiae & 3 & & 3 & & 2.31 & \\
\hline Streptococcus pyogenes & 4 & & 4 & & 2.42 & \\
\hline Other Gram-positive cocci & 14 & & 12 & & & \\
\hline Aerococcus viridans & 6 & & 4 & 2 & 1.73 & \\
\hline Micrococcus luteus & 5 & & 5 & & 1.85 & \\
\hline Rothia mucilaginosa & 3 & & 3 & & 1.91 & \\
\hline Gram-negative bacilli & 461 & & 453 & 8 & & 98.26 \\
\hline Enterobacteriaceae & 386 & & 380 & 6 & & 98.44 \\
\hline Citrobacter freundii & 3 & & 3 & & 2.19 & \\
\hline Citrobacter koseri & 1 & & 1 & & 1.98 & \\
\hline Enterobacter cloacae & 24 & & 23 & 1 & 2.07 & \\
\hline Enterobacter kobei & 2 & & 2 & & 2.23 & \\
\hline Enterobacter aerogenes & 6 & & 6 & & 2.02 & \\
\hline Enterobacter asburiae & 2 & & 2 & & 2.13 & \\
\hline Escherichia coli & 129 & & 128 & 1 & 2.13 & 99.22 \\
\hline
\end{tabular}


Table 2 continued.

\begin{tabular}{|c|c|c|c|c|c|}
\hline Klebsiella pneumoniae & 160 & 156 & 4 & 2.12 & 97.50 \\
\hline Klebsiella oxytoca & 4 & 4 & & 2.07 & \\
\hline Kluyvera ascorbata & 1 & 1 & & 1.98 & \\
\hline Leclercia adecarboxylata & 3 & 3 & & 1.99 & \\
\hline Morganella morganii & 5 & 5 & & 2.29 & \\
\hline Proteus mirabilis & 17 & 17 & & 2.10 & \\
\hline Providencia stuartii & 3 & 3 & & 2.13 & \\
\hline Raoultella ornithinolytica & 8 & 8 & & 2.13 & \\
\hline Salmonella $s p$ & 5 & 5 & & 1.94 & \\
\hline Serratia marcescens & 12 & 12 & & 2.08 & \\
\hline Aeromonas caviae & 1 & 1 & & 2.10 & \\
\hline $\begin{array}{l}\text { Non fermenters Gram- } \\
\text { negative bacilli }\end{array}$ & 67 & 66 & & & 98.50 \\
\hline Acinetobacter baumannii & 31 & 31 & & 1.94 & \\
\hline Acinetobacter nosocomialis & 3 & 3 & & 1.92 & \\
\hline Acinetobacter pittii & 3 & 3 & & 2.12 & \\
\hline Achromobacter xylosoxidans & 1 & & 1 & no peaks & \\
\hline Burkholderia vietnamiensis & 1 & 1 & & 2.05 & \\
\hline Comamonas kerstersii & 1 & 1 & & 1.84 & \\
\hline Pseudomonas aeruginosa & 15 & 15 & & 2.09 & \\
\hline Pseudomonas oryzihabitans & 3 & 3 & & 1.84 & \\
\hline Pseudomonas putida Group & 5 & 5 & & 1.93 & \\
\hline Stenotrophomonas maltophilia & 4 & 4 & & 1.98 & \\
\hline Gram negative cocobacilli & 6 & 6 & & & \\
\hline Haemophilus influenzae & 3 & 3 & & 1.79 & \\
\hline Neisseria meningitidis & 3 & 3 & & 1.75 & \\
\hline Other gram negative bacilli & 1 & & 1 & & \\
\hline Capnocytophaga sputigena & 1 & & 1 & no peaks & \\
\hline Gram positive bacilli & 12 & 10 & 2 & & \\
\hline Corynebacterium jeikeium & 1 & 1 & & 1.98 & \\
\hline Corynebacterium striatum & 4 & 4 & & 1.75 & \\
\hline Corynebacterium imitans & 2 & 2 & & 1.99 & \\
\hline Bacillus cereus & 2 & 2 & & 2.11 & \\
\hline Brevibacterium ravenspurgense & 1 & & 1 & no peaks & \\
\hline Lactococcus lactis & 1 & 1 & & 2.33 & \\
\hline Listeria monocytogenes & 1 & & 1 & no peaks & \\
\hline Anaerobes & 13 & 11 & 2 & & 84.61 \\
\hline Clostridium perfringens & 6 & 6 & & 2.04 & \\
\hline Fusobacterium mortiferum & 1 & 1 & & 2.16 & \\
\hline Peptostreptococcus anaerobius & 1 & 1 & & 1.95 & \\
\hline Propionibacterium acnes & 5 & 3 & 2 & 1.76 & \\
\hline Yeasts & 5 & & 5 & & \\
\hline Candida albicans & 3 & & 3 & no peaks & \\
\hline Candida tropicalis & 1 & & 1 & no peaks & \\
\hline \multirow[t]{2}{*}{ Candida parapsilosis } & 1 & & 1 & no peaks & \\
\hline & 1101 & & 1037 & & \\
\hline
\end{tabular}

Id = Identification

false negative patinas corresponding to 2 Enterobacter cloacae with OXA 163. The carbapenemases detected by the BCT were 24 KPC from 22 Klebsiella pneumoniae, one Escherichia coli, one Serratia marcescens; 3 MBL from two Acinetobacter baumannii with NDM and one Pseudomonas putida with VIM. The average turnaround time of BCT for the detection of KPC was 10 minutes and $1.30 \mathrm{~h}$ for 
Table 3. Microorganisms that were consider contaminants

\begin{tabular}{|c|c|c|c|c|c|c|}
\hline Microorganisms & Number & $\begin{array}{c}\% \text { of } \\
\text { isolates }\end{array}$ & Id & No Id & $\begin{array}{l}\text { Average } \\
\text { score }\end{array}$ & $\begin{array}{c}\% \text { of } \\
\text { identification }\end{array}$ \\
\hline Staphylococcus capitis & 10 & & 8 & 2 & 1.86 & \\
\hline Staphylococcus caprae & 1 & & 1 & & 1.7 & \\
\hline Staphylococcus cohnii & 2 & & 2 & & 1.7 & \\
\hline Staphylococcus epidermidis & 143 & & 130 & 13 & 1.83 & 90.9 \\
\hline Staphylococcus haemolyticus & 36 & & 32 & 4 & 1.79 & 88.8 \\
\hline Staphylococcus hominis & 44 & & 36 & 12 & 1.92 & 81.8 \\
\hline Staphylococcus saprophyticus & 1 & & 1 & & 1.82 & \\
\hline Staphylococcus lugdunensis & 4 & & 4 & & 2.33 & \\
\hline Staphylococcus simulans & 3 & & 3 & & 1.99 & \\
\hline Staphylococcus schleiferi & 1 & & 1 & & 1.68 & \\
\hline Staphylococcus xylosus & 3 & & 3 & & 1.98 & \\
\hline Staphylococcus pseudintermedius & 2 & & 2 & & 1.98 & \\
\hline Staphylococcus pettenkoferi & 1 & & 1 & & 1.75 & \\
\hline Streptococcus salivarius & 7 & & 7 & & 1.99 & \\
\hline Aerococcus viridans & 6 & & 4 & 2 & 1.73 & \\
\hline Micrococcus luteus & 5 & & 5 & & 1.85 & \\
\hline Rothia mucilaginosa & 3 & & 3 & & 1.91 & \\
\hline Bacillus cereus & 2 & & 2 & & 2.11 & \\
\hline Brevibacterium ravenspurgense & 1 & & & 1 & no peaks & \\
\hline Propionibacterium acnes & 5 & & 3 & 2 & 1.76 & \\
\hline Total & 280 & & 248 & & & 88.8 \\
\hline
\end{tabular}

Id = Identification

MBL. In $27(93.10 \%)$ microorganisms we have detectet earlier the carbapenemase resistance. The specificity and sensitivity of BCT were $100 \%$ and $93.55 \%$, respectively, linking molecular method, and the positive and negative predictive values were respectively $100 \%$ and $98.23 \%$ comparing with molecular routine. These results are showed in Table 4. Based on the data obtained, we propose the flow chart shown in Fig. 1.

\section{DISCUSSION}

The results of positive blood cultures should be quickly or promptly available to guide the treatment of critically ill patients. Conventional diagnoses are based on isolated colonies of $24 \mathrm{~h}$ solid media. Species identification could be accelerated by the use of MALDI-TOF MS if short growth patinas in solid medium are used [16]. These results are usually not 
Table 4. Carbapenemases in 29 hospitalized patients

\begin{tabular}{llc}
\hline $\begin{array}{l}\text { Resistance } \\
\text { mechanism }\end{array}$ & Microorganism & N \\
\hline KPC & Klebsiella pneumoniae & 22 \\
KPC & Escherichia coli & 1 \\
KPC & Serratia marcecens & 1 \\
MLB & Acinetobacter baumanii (NDM) & 2 \\
MLB & Pseudomonas putida (VIM) & 1 \\
OXA 163 & $\begin{array}{l}\text { Enterobacter cloacae (False } \\
\text { Negative) }\end{array}$ & 2 \\
\hline
\end{tabular}

used to initiate antibiotic therapy, but rather to assess whether the initial empirical therapy was accurate and otherwise to adjust it [17]. In general, blood culture identification techniques take one day of incubation, and although subsequent staining of Gram can be performed in several minutes, the result of this technique alone does not provide enough information to properly administer adequate antibiotic therapy. Therefore, additional testing should be performed in order to properly identify the pathogen causing the disease, leading to an increase in time to initiate appropriate antibiotic therapy [18].

Previous work has shown that the identification obtained with MALDI-TOF MS from subcultures of very few hours of incubation is concordant with that obtained with the conventional technique of identification from subcultures of 18-24h [19-23].

In order to reduce identification times, different extraction techniques have been attempted, which are performed directly from the positive blood culture bottles. So, as to obtain a sample suitable for identification with the MALDI-TOF MS, it should not be forgotten that the proper proteins of the blood can interfere with the identification [17]. These procedures take time and are laborious, and in some cases, the identification is not achieved [2]. In a study that we have done in our hospital comparing Sepsytiper with an in-house procedure, we have obtained better results with the later procedure, compared to most of extraction procedures, commercially, and in-house [2, 3, 22-24].

In a study of 925 positive blood cultures bottles (representing 470 bacteremic episodes), Verroken et al. [25] obtained a correct identification in 727 (81.1\% of the 896 monomicrobial blood cultures), In Grampositive cocci $85.6 \%$ and in $92.7 \%$ of the enterobacteria and in $94.1 \%$ of the non-fermenters Gram-negative bacilli; with failure being mostly observed with anaerobes and yeasts. Bazzi et al. [20] evaluated 4 methods of blood culture procedures, and in one of them, the pellet of the extraction tubes was cultured in blood agar plates, which were incubated during 90-180 min, obtaining the identification of $94.5 \%$ of the microorganisms. Curtoni et al. [4] also evaluated the growth of short-incubation patinas obtaining about $92.2 \%$ of the Gram-positive cocci; $93.1 \%$ of the Gram-negative bacilli and $66.7 \%$ of the non-fermenters. Hong et al. [26] analyzed 175 microbial blood cultures evaluating bacterial growth between 4-6 h, of which 50.9\% were Gram-positive and $49.1 \%$ were Gram-negative bacteria. They achieved a concordance of $98.9 \%$ at the gender level compared to conventional biochemical tests. Finally, Kohlmann et al. [27] reached similar percentages by performing tests on short incubation subcultures.

Regarding Enterobacteriaceae, the percentage of identification in our study was high $98.44 \%$ and the bacterial grow as patina has been seen in $4 \mathrm{~h}$ or less. About the non fermenting Gram-negative bacilli, it took $5 \mathrm{~h}$ for the observation of the patina, and the identification success was $98.5 \%$.

With the Gram-positive cocci we obtained identification in $92.30 \%$ of the microorganisms; $86.75 \%$ in coagulase negative staphylococci (CNS) and $98.44 \%$ in Staphylococcus aureus. There was a great difference between CNS and Staphylococcus aureus identification times. In CNS the growth of the patina was much slower and we have to incubate them at least $5 \mathrm{~h}$. The early identification of the CNS in one of two blood cultures, allows us to foresee the possibility of skin contaminants. In our study we considered skin contaminated (280) $27.00 \%$ of the 1037 bottles. Thus we contributed to reduce time and costs and avoided the use of unncessary antibiotic therapy.

In the polimicrobial blood culture bottles, the concomitant presence of two different bacteria could be anticipated in some instances by Gram staining. We must highlight that the correct interpretation of the Gram staining from the positive blood culture bottles has a great impact on the microorganisms' identification, in this way, we were able to obtain 
anaerobic identifications in $4 \mathrm{~h}$ since they were incubated in an anaerobic atmosphere.

The BCT for 140 blood cultures from hospitalized patients with Gram-negative bacilli allowed reevaluating or initiating the antibiotic approach in the presence of carbapenemase-producing bacteria. As for the isolated bacteria tested, we obtained 29 carbapenemase resistant $(20.71 \%) ; 27$ were detectet quickly with the BCT (93.10\%); the majority of them came from the intensive unit therapy, wich is our hospital epidemiology. We believe that the performance of MALDI-TOF MS identification after short-term subculture is directly related to the sufficient growth of microorganisms.

The quickly bacterial identification from the patinas has the advantage of performing no previous treatments on the sample; it is an easy method and greatly reduces the time and material used. It can be used together with local antibiotic resistance data in order to optimize the empiric antimicrobial treatment. $\mathrm{BCT}$ is an early diagnostic tool to guide an appropriate treatment in order to reduce the mortality associated with the infections caused by these multi-resistant bacteria.

\section{CONCLUSION}

The use of patina for BCT and early identification by MALDI-TOF MS, is a powerful tool that shortens time and helps select appropriate antibiotic therapy. This benefits the patient. Limitation of the patina MALDI-TOF MS identification was also observed for mixed bloodstream infection, where only one bacterium could be identified.

In conclusion, the application of MALDI-TOF MS identification to rapid growth microorganism obtained from positive blood culture allows an early identification of the most important microorganisms growing in blood culture such as Staphylococcus aureus and Eenterobacteriaceae which is important for the management of nosocomial and community bloodstream infections. Laboratory automation and work flow optimization may play an important role in reducing the microbiology results turnaround time.

\section{Conflict of interest}

The authors disclosed no conflict of interest during the preparation or publication of this manuscript.

\section{Financing}

The authors disclosed that they did not receive any grant during conduction or writing of this study.

\section{Acknowledgements}

We are grateful to Tamara Posse and Luis Aquino for their technical assistance.

\section{REFERENCES}

1. Kang CI, Kim SH, Park WB, Lee KD, Kim HB, Kim EC, et al. Bloodstream infections caused by antibiotic-resistant gramnegative bacilli: risk factors for mortality and impact of inappropriate initial antimicrobial therapy on outcome. Antimicrob Agents Chemother 2005;49:760-6.

2. Cattani ME, Posse T, Hermes R, Kaufman S. [Rapid identification of microorganisms by mass spectrometry in a blood culture system. Comparison of two procedures]. Rev Argent Microbiol 2015;47:190-5. [Article in Spanish]

3. Prod'hom G, Bizzini A, Durussel C, Bille J, Greub G. Matrixassisted laser desorption ionization-time of flight mass spectrometry for direct bacterial identification from positive blood culture pellets. J Clin Microbiol 2010;48:1481-3.

4. Curtoni A, Cipriani R, Marra Barbui AM, Cavallo R, Costa C. Rapid identification of microorganisms from positive blood culture by MALDI-TOF MS after short-term incubation on solid medium. Curr Microbiol 2017;74:97-102.

5. Prod'hom G, Bizzini A, Durussel C, Bille J, Greub G. Matrixassisted laser desorption ionization-time of flight mass spectrometry for direct bacterial identification from positive blood culture pellets. J Clin Microbiol 2010;48:1481-3.

6. Stevenson L, Drake S, Murray P. Rapid identification of bacteria in positive blood culture broths by matrix-assisted laser desorption ionization-time of flight mass spectrometry. J Clin Microbiol 2010;48:444-7.

7. Cogut S, Errecalde L, Cattani M, Kaufman S. Desempeño del ensayo colorimétrico Blue Carba Test en la detección de bacterias portadoras de carbapenemasas. ALAM-CAM, 2016, Poster JU1062, Rosario, Santa Fe, Argentina.

8. Clark A, Kaleta E, Arora A, Wolk D. Matrix-assisted laser desorption ionization time of flight mass spectrometry: a fundamental shift in the routine practice of clinical microbiology. Clin Microbiol Rev 2013;26:547-603.

9. De Bel A, Wybo I, Vandoorslaer K, Rosseel P, Lauwers S, Piérard D. Acceptance criteria for identification results of Gramnegative rods by mass spectrometry. J Med Microbiol 2011;60:684-6.

10. Vlek A, Boten M, Boel C. Direct matrix-assisted laser desorptionionization time-of-flight mass spectrometry improves appropriateness of antibiotic treatment of bacteremia. PloS One 2012;7:e32589.

11. Centers for Disease Control and Prevention/National 
Healthcare Safety Network (CDC/NHSN) (2014) CDC/NHSN surveillance definitions for specific types of infections. Available online at: http:// www.cdc.gov/nhsn/pdfs/pscmanual/17 pscnosinfdef_current.pdf. Accessed 19 June 2014

12. Pasteran $\bar{F}$, Veliz O, Lucero C, Rapoport M, Ceriana P, Corso A. Blue-Carba Test (BCT) for Rapid Detection of Carbapenemases in Gram-negative Species: Performance against a Panel of Challenging Carbapenemases. 54th ICAAC, Abstract 963; 2014.

13. Pasteran F, Veliz O, Ceriana P, Lucero C, Rapoport M, Albornoz E, et al.; ReLAVRA Network Group. Evaluation of the Blue-Carba test for rapid detection of carbapenemases in gramnegative bacilli. J Clin Microbiol 2015;53:1996-8.

14. Pasteran F, Mendez T, Guerriero L, Rapoport M, Corso A. Sensitive screening tests for suspected class A car bapenemase production in species of Enterobacteriaceae. J Clin Microbiol 2009;47:1631-9.

15. Pasteran F, Veliz O, Lucero C, Guerriero L, Ceriana P, Cogut $\mathrm{S}$, et al. Evaluación de un equipo comercial de discos combinados de meropenem (DCM-brit) para la detección de KPC, MBL y OXA basado en innovadoras combinaciones de inhibidores. XIII Congreso Argentino de Microbiologia, Ciudad de Buenos Aires, 23 al 26 de septiembre 2013.

16. Köck R, Wüllenweber J, Horn D, Lanckohr C, Becker K, Idelevich E. Implementation of short incubation MALDITOF MS identification from positive blood cultures in routine diagnostics and effects on empiric antimicrobial therapy. Antimicrob Resist Infect Control 2017;6:12.

17. Köck R, Kipp F, Ellger B. [Blood culture diagnosticchallenge or routine standard of care?]. Anasthesiol Intensivmed Notfallmed Schmerzther 2015;50:124-31. [Article in German] 18. Loonen AJ, Jansz AR, Stalpers J, Wolffs PF, van den Brule AJ. An evaluation of three processing methods and the effect of reduced culture times for faster direct identification of pathogens from BacT/ALERT blood cultures by MALDI-TOF MS. Eur J Clin Microbiol Infect Dis 2012;31:1575-83.

19. Ballestero-Téllez M, Recacha E, de Cueto M, Pascual Á.
Identification and antimicrobial susceptibility testing of positive blood culture isolates from briefly incubated solid medium cultures. Enferm Infecc Microbiol Clin 2017;35:582-5.

20. Bazzi AM, Rabaan AA, El Edaily Z, John S, Fawarah MM, Al-Tawfiq JA. Comparison among four proposed direct blood culture microbial identification methods using MALDI-TOF MS. J Infect Public Health 2017;10:308-15.

21. Bhatti MM, Boonlayangoor S, Beavis KG, Tesic V. Rapid identification of positive blood cultures by matrix-assisted laser desorption ionization-time of flight mass spectrometry using prewarmed agar plates. J Clin Microbiol 2014;52:4334-8.

22. Köck J, Thomas L, Olma T, Chen S, Iredell J. Identification of bacteria in blood culture broths using matrix-assisted laser desorption-ionization Sepsityper and time of flight mass spectrometry. PloS One 2011;6:e23885.

23. Idelevich EA, Schüle I, Grünastel B, Wüllenweber J, Peters $\mathrm{G}$, Becker K. Rapid identification of microorganisms from positive blood cultures by MALDITOF mass spectrometry subsequent to very short-term incubation on solid medium. Clin Microbiol Infect 2014;20:1001-6.

24. La Scola B, Raoult D. Direct identification of bacteria in positive blood culture bottles by matrix-assisted laser desorption ionisation time-of-flight mass spectrometry. PloS One 2009;4:e8041.

25. Verroken A, Defourny L, Lechgar L, Magnette A, Delmée M, Glupczynski Y. Reducing time to identification of positive blood cultures with MALDI-TOF MS analysis after a 5-h subculture. Eur J Clin Microbiol Infect Dis 2015;34:405-13.

26. Hong SK, Chang BK, Song SH, Kim EC. Use of MALDITOF MS technique for rapid identification of bacteria from positive blood cultures. Indian J Med Microbiol 2014;32:419-22. 27. Kohlmann R, Hoffmann A, Geis G, Gatermann S. MALDITOF mass spectrometry following short incubation on a solidmedium is a valuable tool for rapid pathogen identification from positive blood cultures. Int J Med Microbiol 2015;305:46979. 